\title{
Repeat aortic valve replacement for failing aortic root homograft
}

\author{
Ahmed F. Sedeek, MD, ${ }^{a}$ Kevin L. Greason, MD, ${ }^{a}$ Vuyisile T. Nkomo, MD, MPH, ${ }^{b}$ Mackram F. Eleid, MD, ${ }^{b}$ \\ Simon Maltais, MD, PhD, ${ }^{a}$ Eric E. Williamson, MD, ${ }^{\mathrm{c}}$ Juan A. Crestanello, MD, ${ }^{a}$ David R. Holmes, Jr, MD, ${ }^{b}$ \\ Gurpreet S. Sandhu, MD, PhD, ${ }^{b}$ and Hartzell V. Schaff, $\mathrm{MD}^{\mathrm{a}}$
}

\section{ABSTRACT}

Objective: Published data are limited in comparison of transcatheter aortic valve replacement with surgical aortic valve replacement for the failing aortic root homograft. We reviewed our experience with repeat aortic valve replacement in failing aortic root homografts to compare outcomes of transcatheter aortic valve replacement and surgical aortic valve replacement.

Methods: We retrospectively reviewed the records of 51 patients with failing aortic root homografts who received repeat aortic valve replacement between October 2000 and May 2018. Operation included transcatheter aortic valve replacement in 11 patients between June 2014 and May 2018. Surgical aortic valve replacement was performed in 40 patients between October 2000 and January 2018, and operation included repeat composite aortic valve/root replacement in 30 patients $(75 \%)$.

Results: Patient age was 59 years (interquartile range, 50-72 years), sex was female in 9 patients $(18 \%)$, and time to repeat aortic valve replacement was 12 years (interquartile range, 8-13). Procedure-related complications occurred in 37 patients $(73 \%)$ : vascular injury (any) more commonly in the transcatheter aortic valve replacement group ( $36 \%$ vs $5 \% ; P=.015$ ), bleeding (major or lifethreatening) more commonly in the surgical aortic valve replacement group $(58 \%$ vs $0 \% ; P<.001)$, and sternal reentry injury only in the surgical aortic valve replacement group $(\mathrm{n}=6,15 \%)$. There were 3 procedure-related deaths in the surgical aortic valve replacement group $(8 \%)$ and $1(9 \%)$ in the transcatheter aortic valve replacement group $(P=1.000)$. Subsequent cardiac operation occurred in no patients in the transcatheter aortic valve replacement group and in 5 patients in the surgical aortic valve replacement group.

Conclusions: Repeat aortic valve replacement for failing aortic root homograft is associated with notable risk of morbidity and mortality regardless of replacement technique. Avoidance of vascular injury could lead to improved outcomes in the transcatheter aortic valve replacement group. (J Thorac Cardiovasc Surg

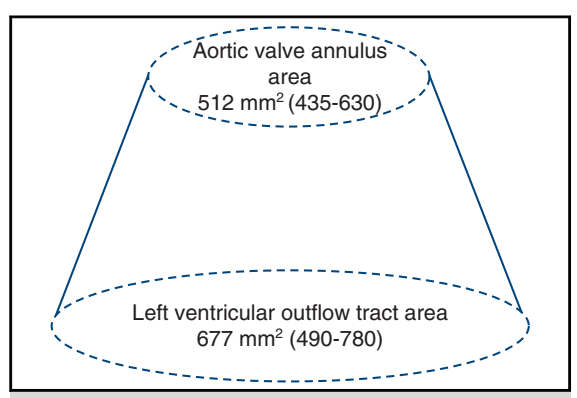

Conical frustum shape of the failing aortic root homograft.

\section{Central Message}

Repeat aortic valve replacement of a failing aortic root homograft is associated with notable rates of morbidity and mortality regardless of replacement technique.

\section{Perspective}

Repeat aortic valve replacement of a failing aortic root homograft is associated with notable risk of morbidity and mortality regardless of replacement technique. TAVR is associated with a low rate of transfusion and short hospital length of stay. Avoidance of vascular injury could lead to improved outcomes in the transcatheter group.

See Commentaries on pages 386, 388 and 390 . 2019;158:378-85)

\footnotetext{
From the Departments of a Cardiovascular Surgery, ${ }^{\mathrm{b}}$ Cardiovascular Diseases, and ${ }^{\mathrm{c} R a d i o l o g y, ~ M a y o ~ C l i n i c, ~ R o c h e s t e r, ~ M i n n . ~}$

Funded by the Mayo Clinic.

Date and number of Institutional Review Board approval: approved May 9, 2018, Number 18-004238.

Received for publication June 11, 2018; revisions received Nov 3, 2018; accepted for publication Nov 28, 2018; available ahead of print Jan 18, 2019

Address for reprints: Kevin L. Greason, MD, Department of Cardiovascular Surgery, Mayo Clinic, 200 First St SW, Rochester, MN 55905 (E-mail: greason.kevin@ mayo.edu).

$0022-5223 / \$ 36.00$

Copyright $₫ 2018$ Published by Elsevier Inc. on behalf of The American Association for Thoracic Surgery

https://doi.org/10.1016/j.jtcvs.2018.11.107
}

Aortic valve replacement can be a technical challenge in patients with a failing aortic root homograft. ${ }^{1-5}$ Upwards of $50 \%$ of such patients may require repeat aortic root replacement. ${ }^{1,2}$ Sternal entry injury and need for

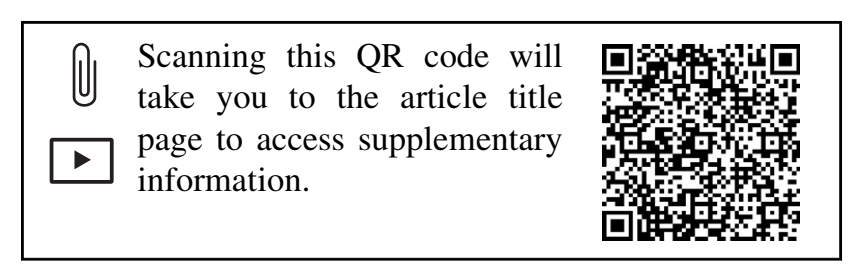




\section{Abbreviations and Acronyms \\ $\mathrm{IQR}=$ interquartile range \\ SAVR $=$ surgical aortic valve replacement \\ TAVR $=$ transcatheter aortic valve replacement}

concomitant cardiac procedures are also common in this setting. ${ }^{1-5}$ Transcatheter aortic valve replacement (TAVR) represents a contemporary alternative option, but there are limited published data and experience with the technique in comparison with surgical aortic valve replacement (SAVR). ${ }^{4,6-13}$ We reviewed our experience with repeat aortic valve replacement in failing aortic root homografts to compare outcomes of TAVR with SAVR.

\section{MATERIALS AND METHODS Patients}

This study was approved by the Mayo Clinic Rochester Institutional Review Board. We retrospectively reviewed the records of 54 consecutive patients with failing aortic root homografts who received repeat aortic valve replacement at the Mayo Clinic between October 2000 and May 2018. We excluded 3 patients with active infective aortic valve endocarditis. The remaining 51 patients were classified by the type of repeat aortic valve replacement. Operation included TAVR in 11 patients between June 2014 and May 2018 and SAVR in 40 patients between October 2000 and January 2018. The primary indication for operation was to treat the failing aortic root homograft.

The first TAVR was performed in June 2014 (Figure 1). Before that date, 30 patients $(75 \%)$ received SAVR because that was the only procedure option for repeat aortic valve replacement. Since the date of the first TAVR procedure, 10 SAVRs have been performed. In the last 5 procedures, 4 $(80 \%)$ were performed with the transcatheter technique. The decision to offer TAVR or SAVR was at the discretion of the heart team. There has been no formal institutional-defined technique for repeat aortic valve replacement. Technical aspects of the operation were at the discretion of the operating surgeon; however, all surgical patients received cold blood cardioplegia. Transcatheter aortic valve insertion was performed on the basis of standard instructions for use (Video 1). ${ }^{14,15}$

\section{Definitions}

Patient baseline, operative, and follow-up data were abstracted from the medical record based on definitions set forth in the Society of Thoracic

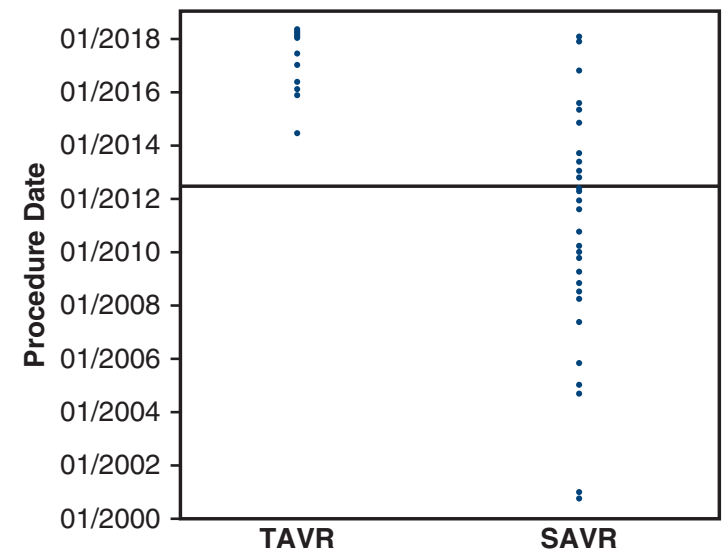

FIGURE 1. Procedure date stratified by operative procedure. TAVR, Transcatheter aortic valve replacement; $S A V R$, surgical aortic valve replacement.

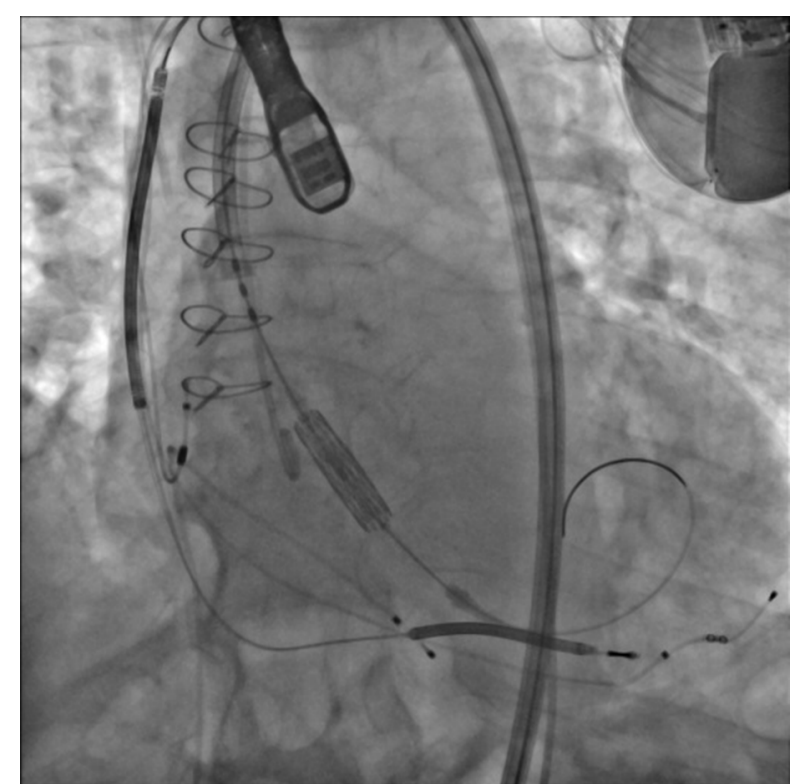

VIDEO 1. Transcatheter aortic valve insertion in homograft. Video available at: https://www.jtcvs.org/article/S0022-5223(18)33257-4/fulltext.

Surgeons Adult Cardiac Database (Chicago, Ill). The primary end point of the study was operative death, defined as any death occurring during the hospitalization and those occurring after discharge, but within 30 days of the procedure. Secondary end points included procedurerelated complications. We used Society of Thoracic Surgery definitions for myocardial infarction, stroke, atrial fibrillation, need for mechanical circulatory support, or permanent pacemaker insertion. We used the Valve Academic Research Consortium 2 definitions for bleeding (major or life threatening defined as requiring $>2$ units of packed red blood cells) and vascular injury (included major, minor, or percutaneous closure device related). ${ }^{16}$

Clinical follow-up for the occurrence of repeat operation was obtained through review of the electronic medical record and cardiac surgery patient surveys completed postoperatively at $1,3,5,10,15$, and 20 years by the Department of Cardiovascular Surgery, Mayo Clinic, Rochester, Minnesota. Vital status was checked through the electronic medical record, postoperative survey, Accurint (LexisNexis, New York, NY) locate-and-research tool, and an internet search that included a general obituary query.

\section{Statistical Methods}

Descriptive statistics included median (interquartile range [IQR]) for continuous data and count (percent) for categoric data. Inferential statistics for categoric data for $2 \times 2$ contingency tables used the Fisher exact test, and otherwise the chi-square test. Continuous data in the TAVR group were not normally distributed; therefore, the Wilcoxon nonparametric rank-sum test was used for continuous data. Follow-up was complete in all patients, and length of follow was estimated using the reversed Kaplan-Meier method. Mortality estimates were calculated using the Kaplan-Meier method. The criterion of significance was an alpha value less than or equal to .05. All statistical analyses were performed using JMP Pro 13.0.0 (SAS Institute Inc, Cary, NC).

\section{RESULTS}

\section{Demographics}

Patient age was 59 years (IQR, 50-72), sex was female in 9 patients (18\%), Society of Thoracic Surgeons predicted risk of operative mortality for isolated SAVR was $2.1 \%$ 
TABLE 1. Baseline patient characteristics stratified by operation type

\begin{tabular}{|c|c|c|c|c|c|}
\hline Continuous variable & $\frac{\text { Missing data }}{\text { Count }(\%)}$ & All patients $(\mathrm{n}=\mathbf{5 1})$ & $\frac{\operatorname{TAVR}(\mathrm{n}=11)}{\operatorname{Median}(\mathrm{IQR})}$ & $\underline{\operatorname{SAVR}(n=40)}$ & $P$ value \\
\hline Age (y) & $0(0)$ & $59(50-72)$ & $75(52-79)$ & $58(47-63)$ & .023 \\
\hline Body mass index $\left(\mathrm{kg} / \mathrm{m}^{2}\right)$ & $0(0)$ & $27(24-32)$ & $24(22-31)$ & $29(25-32)$ & .049 \\
\hline Preoperative creatinine $(\mathrm{mg} / \mathrm{dL})$ & $0(0)$ & $1.1(1.0-1.3)$ & $1.0(0.9-1.3)$ & $1.1(1.0-1.3)$ & .169 \\
\hline Ejection fraction $(\%)$ & $0(0)$ & $55(50-62)$ & $54(49-59)$ & $57(50-66)$ & .247 \\
\hline Society of Thoracic Surgeons predicted risk of mortality $(\%)$ & $0(0)$ & $2.1(1.5-3.6)$ & $2.4(1.8-6.1)$ & $2.0(1.5-3.5)$ & .233 \\
\hline Time to repeat aortic valve replacement (y) & $0(0)$ & $12(8-13)$ & $15(12-19)$ & $10(6-13)$ & .005 \\
\hline Follow-up (y) & $0(0)$ & $5.6(2.9-8.1)$ & $1.0(0.1-1.9)$ & $7.8(5.3-8.8)$ & $<.001^{*}$ \\
\hline Years of study & $0(0)$ & $2000-2018$ & $2014-2018$ & $2000-2018$ & \\
\hline \multicolumn{6}{|l|}{ Categoric variable } \\
\hline Female sex & $0(0)$ & $9(18)$ & $2(18)$ & $7(18)$ & 1.000 \\
\hline Diabetes & $0(0)$ & $2(4)$ & $0(0)$ & $2(5)$ & 1.000 \\
\hline Hypertension & $0(0)$ & $25(49)$ & $6(55)$ & $19(48)$ & .171 \\
\hline Dialysis & $0(0)$ & $1(2)$ & $0(0)$ & $1(3)$ & 1.000 \\
\hline Infectious endocarditis, treated & $0(0)$ & $17(33)$ & $4(36)$ & $13(34)$ & .810 \\
\hline Chronic lung disease, severe & $0(0)$ & $1(2)$ & $1(9)$ & $0(0)$ & .216 \\
\hline Immunosuppression & $0(0)$ & $1(2)$ & $0(0)$ & $1(3)$ & 1.000 \\
\hline Peripheral vascular disease & $0(0)$ & $3(6)$ & $2(18)$ & $1(3)$ & .114 \\
\hline Cerebrovascular diseases & $0(0)$ & $10(20)$ & $2(18)$ & $8(20)$ & 1.000 \\
\hline Coronary artery disease & $0(0)$ & $18(35)$ & $2(18)$ & $16(40)$ & .288 \\
\hline Previous coronary artery bypass graft operation & $0(0)$ & $10(20)$ & $1(9)$ & $9(23)$ & .428 \\
\hline No. of diseased coronary arteries, $\geq 1$ & $0(0)$ & $18(35)$ & $2(18)$ & $16(40)$ & .288 \\
\hline Left main coronary artery stenosis $>50 \%$ & $0(0)$ & $5(10)$ & $2(18)$ & $3(8)$ & .291 \\
\hline Previous pacemaker & $0(0)$ & $13(25)$ & $5(45)$ & $8(20)$ & .086 \\
\hline New York Heart Association functional class III or IV & $0(0)$ & $23(45)$ & $7(64)$ & $16(40)$ & .190 \\
\hline Cardiogenic shock & $0(0)$ & $0(0)$ & $0(0)$ & $0(0)$ & \\
\hline Resuscitation & $0(0)$ & $0(0)$ & $0(0)$ & $0(0)$ & \\
\hline Atrial fibrillation & $0(0)$ & $19(37)$ & $2(18)$ & $17(43)$ & .140 \\
\hline Medical inotropes & $0(0)$ & $2(4)$ & $0(0)$ & $2(5)$ & 1.000 \\
\hline Aortic valve stenosis, mild or greater & $0(0)$ & $31(61)$ & $11(100)$ & $20(50)$ & .003 \\
\hline Mitral valve stenosis, mild or greater & $0(0)$ & $5(10)$ & $4(36)$ & $1(3)$ & .006 \\
\hline Aortic valve regurgitation, moderate or severe & $0(0)$ & $47(92)$ & $11(100)$ & $36(90)$ & .565 \\
\hline Mitral valve regurgitation, moderate or severe & $0(0)$ & $10(20)$ & $2(18)$ & $4(10)$ & 1.000 \\
\hline Tricuspid valve regurgitation, moderate or severe & $0(0)$ & $10(20)$ & $1(9)$ & $9(23)$ & .428 \\
\hline No. of previous sternotomies & $0(0)$ & & & & $.144 \dagger$ \\
\hline 1 & & $36(71)$ & $7(64)$ & $29(73)$ & \\
\hline 2 & & $12(24)$ & $2(18)$ & $10(25)$ & \\
\hline 3 & & $3(6)$ & $2(18)$ & $1(3)$ & \\
\hline Operative status, urgent & $0(0)$ & $9(18)$ & $1(9)$ & $8(20)$ & .663 \\
\hline
\end{tabular}

Continuous data were analyzed with the nonparametric rank-sum test. TAVR, Transcatheter aortic valve replacement; $S A V R$, surgical aortic valve replacement; $I Q R$, interquartile range. *Follow-up data were analyzed with reverse Kaplan-Meier estimator method and are reported with $95 \%$ CIs. †Categoric data were analyzed with the Fisher exact with exception of the $2 \times 3$ contingency table that was analyzed with the chi-square test.

(IQR, 1.5-3.6), and time interval to repeat aortic valve operation was 12 years (IQR, 8-13). Baseline patient characteristics stratified by operation type are shown in Table 1 . Patients in the TAVR group were older (75 vs 58 years; $P=.023)$ and had a greater proportion of aortic valve stenosis $(100 \%$ vs $50 \% ; P=.003)$ and mitral valve stenosis $(36 \%$ vs $3 \% ; P=.006)$ in comparison with patients who received SAVR (Table 1). The indications of the primary and repeat operation are listed in Table 2.

\section{Surgical Aortic Valve Replacement}

SAVR was performed in 40 patients. Operations included aortic valve replacement in 10 patients $(25 \%)$ and repeat composite aortic valve/root replacement in 30 patients $(75 \%)$. Mechanical valves were implanted in 33 patients $(83 \%)$, stented biological valves in 6 patients $(15 \%)$, and a stentless biological valve in 1 patient $(3 \%)$. Concomitant operative cardiac procedures were performed in 23 patients $(58 \%)$ and included replacement of the distal ascending 
TABLE 2. Indications for operation

\begin{tabular}{lccc}
\hline & All patients $(\mathbf{n}=\mathbf{5 1})$ & TAVR $(\mathbf{n}=\mathbf{1 1})$ & SAVR $(\mathbf{n}=\mathbf{4 0})$ \\
\hline Index homograft operation indication, Count $(\%)$ & & & \\
$\quad$ Aortic valve regurgitation, severe & $13(25)$ & $3(27)$ & $10(25)$ \\
Aortic valve stenosis, severe & $13(25)$ & $3(27)$ & $10(25)$ \\
Infective endocarditis & $16(31)$ & $4(36)$ & $12(30)$ \\
Unknown & $8(16)$ & $1(9)$ & $7(18)$ \\
Aortic root aneurysm & $1(2)$ & $0(0)$ & $1(3)$ \\
Repeat aortic valve replacement indication, Count $(\%)$ & $38(75)$ & $9(82)$ & $29(73)$ \\
Aortic valve regurgitation, severe & $3(6)$ & $0(0)$ & $3(8)$ \\
Aortic valve stenosis, severe & $10(20)$ & $2(18)$ & $8(20)$ \\
Combined aortic valve regurgitation and stenosis & & .625 \\
\hline
\end{tabular}

Categoric data were analyzed with the chi-square exact test. TAVR, Transcatheter aortic valve replacement; SAVR, surgical aortic valve replacement.

aorta in $11(28 \%$, which included 8 patients with hemi-arch replacement), coronary artery bypass graft operation in 7 $(18 \%)$, aortic root enlargement in $7(18 \%)$, mitral valve operation in $6(15 \%)$, and tricuspid valve operation in 3 $(8 \%)$. The Cabrol modification was performed in 5 patients $(17 \%)$ in the repeat composite aortic valve/root replacement group. Additional operative data are reported in Table E1.

\section{Transcatheter Aortic Valve Replacement}

TAVR was performed in 11 patients $(22 \%)$. Anesthesia was conscious sedation in 5 patients $(45 \%)$ and general endotracheal in 6 patients $(55 \%)$. Arterial access was through the femoral artery in 9 patients $(82 \%)$, axillary artery in 1 patient $(9 \%)$, and left ventricular apex in 1 patient $(9 \%)$. Valve models inserted included the SAPIEN S3 valve in 9 patients $(82 \%)$, SAPIEN XT valve in 1 patient $(9 \%$; both Edwards Lifesciences, Irvine, Calif), and Evolut valve in 1 patient ( $9 \%$; Medtronic, Minneapolis, Minn).
Transcatheter aortic valve size was $29 \mathrm{~mm}$ in 5 patients (45\%), $26 \mathrm{~mm}$ in 5 patients $(45 \%)$, and $23 \mathrm{~mm}$ in 1 patient $(9 \%)$.

In the transcatheter group, computed tomography examination of the aortic root demonstrated that the aortic valve annulus geometric area was smaller than the left ventricular outflow tract geometric area (Table 3). The computed tomography calculated geometric area of the aortic valve annulus area was $512 \mathrm{~mm}^{2}$ (IQR, 435-630), whereas that of the left ventricular outflow tract geometric area was $677 \mathrm{~mm}^{2}$ (IQR, 490-780) $(P=.002)$. The geometric shape is consistent with that of a conical frustum (Figure 2). The transcatheter aortic valve annulus geometric area oversize was $6 \%$ (IQR, 1-18), and the left ventricular outflow tract geometric area oversize was $-17 \%$ (IQR, $-23-10)$. Additional balloon volume was added during the index valve deployment in 6 patients $(55 \%)$ : patient $4,4 \mathrm{~mL}$; patient 5 , $2 \mathrm{~mL}$; patient $6,5 \mathrm{~mL}$; patient $7,1 \mathrm{~mL}$; patient $8,1 \mathrm{~mL}$; and patient $10,3 \mathrm{~mL}$.

TABLE 3. Transcatheter aortic valve replacement data and geometric areas of aortic valve annulus and left ventricular outflow tract

\begin{tabular}{|c|c|c|c|c|c|c|}
\hline \multirow[b]{2}{*}{ Patient } & \multirow[b]{2}{*}{ Valve type } & \multirow[b]{2}{*}{ Valve size $(\mathbf{m m})$} & \multicolumn{2}{|c|}{ Aortic valve annulus } & \multicolumn{2}{|c|}{ Left ventricular outflow tract } \\
\hline & & & $\overline{\operatorname{Area}\left(\mathrm{mm}^{2}\right)}$ & Oversize $(\%)$ & Area $\left(\mathrm{mm}^{2}\right)$ & Oversize $(\%)$ \\
\hline 1 & Sapien XT (Edwards Lifesciences, Irvine, Calif) & 26 & 475 & 12 & 480 & 10 \\
\hline 2 & Evolut (Medtronic, Minneapolis, Minn) & 29 & 350 & 89 & 600 & 10 \\
\hline 3 & Sapien S3 & 26 & 435 & 19 & 677 & -23 \\
\hline $4 *$ & Sapien S3 & 29 & 729 & -11 & 780 & -17 \\
\hline $5^{*}$ & Sapien S3 & 29 & 630 & 3 & 800 & -19 \\
\hline $6^{*}$ & Sapien S3 & 29 & 737 & -12 & 837 & -22 \\
\hline 7 & Sapien S3 & 26 & 516 & 1 & 705 & -26 \\
\hline $8^{*}$ & Sapien S3 & 23 & 385 & 6 & 410 & 0 \\
\hline $9^{*}$ & Sapien S3 & 29 & 580 & 12 & 600 & 8 \\
\hline $10^{*}$ & Sapien S3 & 26 & 512 & 1 & 770 & -33 \\
\hline 11 & Sapien S3 & 26 & 440 & 18 & 490 & 6 \\
\hline
\end{tabular}

*Additional balloon volume added during index valve deployment: patient 4 , additional $4 \mathrm{~mL}$; patient 5 , additional $2 \mathrm{~mL}$; patient 6 , additional $5 \mathrm{~mL}$; patient 7 additional $1 \mathrm{~mL}$; patient 8 , additional $1 \mathrm{~mL}$; and patient 10 , additional $3 \mathrm{~mL}$. 


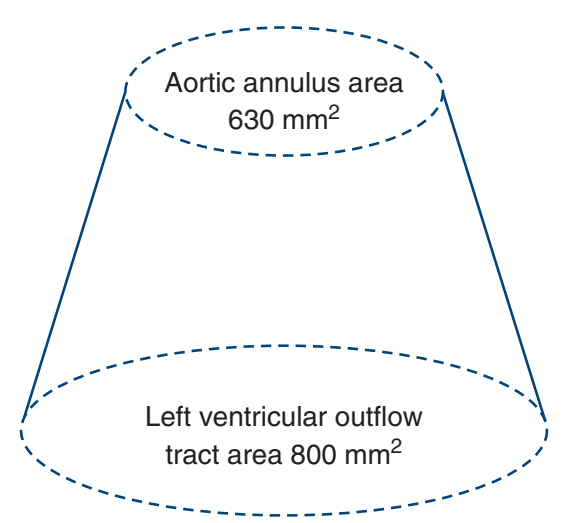

A

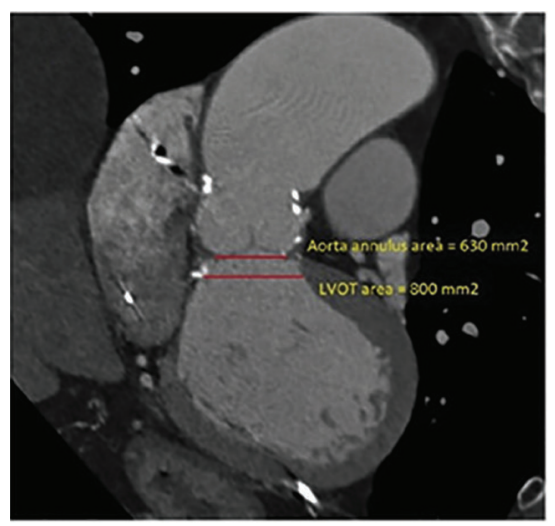

B

FIGURE 2. Conical frustum shape of aortic valve annulus and left ventricular outflow tract: cartoon representation (A) and actual multidetector computed tomography scan (B) (TAVR patient number 5). LVOT, Left ventricular outflow tract.

\section{Hospital Stay-Related Outcomes}

Length of hospital stay was 6 days (IQR, 5-8), and that included 2 days (IQR, 1-6) in the TAVR group and 7 days (IQR 5-9) in the SAVR group $(P<.001)$. Procedurerelated complications occurred in 37 patients $(73 \%)$ : Vascular injury occurred more commonly in the TAVR group ( $36 \%$ vs $15 \% ; P=.193)$, and bleeding (major or life-threatening) occurred more commonly in the SAVR group $(58 \%$ vs $0 \% ; P<.001)$ (Table 4$)$. Sternal entry injury occurred in 6 patients $(15 \%)$ in the SAVR group, and 3 of these patients had a preoperative CT scan completed to guide in repeat sternotomy. There were 3 procedure-related deaths in the SAVR group $(8 \%)$ and 1
$(9 \%)$ in the TAVR group $(P=1.000)$. Causes of death in the SAVR group include low cardiac output syndrome, anoxic brain injury, and ventricular fibrillation; in the transcatheter group, cause of death was traumatic subdural hematoma due to a fall from standing while in the hospital.

\section{Blood Transfusion}

Blood transfusion was common and occurred in 34 patients $(67 \%)$, including $2(18 \%)$ in the TAVR group and $32(80 \%)$ in the SAVR group $(P<.001)$ (Table E2). All measures of blood transfusion were greater in the SAVR group. This included receiving greater than 4 units of

TABLE 4. Procedure-related complications

\begin{tabular}{|c|c|c|c|c|}
\hline Variable & All patients $(n=51)$ & $\operatorname{TAVR}(\mathbf{n}=11)$ & $\operatorname{SAVR}(n=40)$ & $P$ value \\
\hline Any complication & $37(73)$ & $6(55)$ & $31(78)$ & .131 \\
\hline Bleeding (major or life-threatening)* & $23(45)$ & $0(0)$ & $23(58)$ & $<.001$ \\
\hline Atrial fibrillation & $13(25)$ & $1(9)$ & $12(30)$ & .250 \\
\hline Mechanical Circulatory support & $6(12)$ & $0(0)$ & $6(15)$ & .319 \\
\hline Intra-aortic balloon pump & $6(12)$ & $0(0)$ & $6(15)$ & .319 \\
\hline Extracorporeal membrane oxygenation & $2(4)$ & $0(0)$ & $2(5)$ & 1.000 \\
\hline Vascular injury $\dagger$ & $10(20)$ & $4(36)$ & $6(15)$ & .193 \\
\hline Permanent pacemaker (new) & $4 / 43(9)$ & $1 / 8(13)$ & $3 / 35(9)$ & 1.000 \\
\hline Operative death & $4(8)$ & $1(9)$ & $3(8)$ & 1.000 \\
\hline Cardiac arrest & $1(2)$ & $0(0)$ & $1(3)$ & 1.000 \\
\hline Dialysis (new onset) & $1 / 50(2)$ & $0(0)$ & $1 / 39(3)$ & 1.000 \\
\hline Myocardial infarction & $1(2)$ & $0(0)$ & $1(3)$ & 1.000 \\
\hline Stroke (permanent) & $1(2)$ & $0(0)$ & $1(3)$ & 1.000 \\
\hline Length of hospital stay (d) & $6(5-8)$ & $2(1-6)$ & $7(5-9)$ & $<.001$ \\
\hline
\end{tabular}

Categoric data were analyzed with the Fisher exact. TAVR, Transcatheter aortic valve replacement; SAVR, surgical aortic valve replacement. *Valve Academic Research Consortium 2 definition. $\dagger$ TAVR group vascular injuries: femoral artery stenosis from closure device $\mathrm{n}=2$, femoral artery pseudoaneurysm $\mathrm{n}=1$, and iliac artery dissection $\mathrm{n}=1$; SAVR group vascular injuries: pulmonary artery $\mathrm{n}=2$, homograft/innominate vein/superior vena cava/pulmonary artery $\mathrm{n}=1$, posterior descending vein and left ventricular apex $\mathrm{n}=1$, aortic pseudoaneurysm $\mathrm{n}=1$, homograft $\mathrm{n}=1$. 
any blood product $(P<.001)$ and number of units received of packed red blood cells $(P=.002)$, freshfrozen plasma $(P<.001)$, cryoprecipitate $(P=.014)$, and platelets $(P<.001)$. The total number of blood transfusion units was also greater in the SAVR group (7 units, IQR, 1-17) in comparison with the TAVR group (0 units; $P<.001)$.

\section{Postoperative Echocardiography}

Postoperative transthoracic echocardiography was performed in 50 patients $(98 \%)$ at a median of 34 days (IQR, $3-1163$ ). Ejection fraction was $55 \%$ (IQR, 45-62) in the TAVR group and 53\% (IQR, 41-60) in the SAVR group $(P=.783)$. Mean prosthetic transvalvular systolic gradient was $12 \mathrm{~mm} \mathrm{Hg}$ (IQR, 10-18) in the TAVR group and $19 \mathrm{~mm}$ $\mathrm{Hg}$ (IQR, 11-24) in the SAVR group $(P=.085)$. A gradient of more than $20 \mathrm{~mm} \mathrm{Hg}$ was noted in 1 patient $(9 \%)$ in the TAVR group and in 15 patients $(38 \%)$ in the SAVR group $(P=.080)$. Aortic paravalvular regurgitation was grade none in 32 patients $(82 \%)$ and trivial in 7 patients $(18 \%)$ in the SAVR group, and none in 5 patients $(45 \%)$, trivial in 5 patients $(45 \%)$, and moderate in 1 patient $(9 \%$; patient number 2, Evolut valve) in the TAVR group.

\section{Survival}

The estimated Kaplan-Meier duration of vital status follow-up was 5.6 years $(95 \%$ confidence interval [CI], 2.9-8.1), which included 1.0 year $(95 \% \mathrm{CI}, 0.1-1.9)$ in the TAVR group and 7.8 years $(95 \% \mathrm{CI}, 5.3-8.8)$ in the SAVR group $(P<.001)$. During those follow-up periods, 2 patients $(18 \%)$ died in the TAVR group, and 12 patients $(30 \%)$ died in the SAVR group. The deaths in the TAVR group occurred at 39 and 900 days after operation. The patient in the TAVR group who died at 900 days (2.5 years) postoperatively was aged 83 years at the time of the TAVR procedure. In the group of patients in the SAVR group who survived operation, death occurred at the following time intervals postoperatively: 1.5, 1.8, $2.3,2.5,5.2,5.5,6.9,7.7$, and 14.3 years. KaplanMeier estimates of mortality in the SAVR group were $8 \% \pm 4 \%$ at 1 year, $20 \% \pm 7 \%$ at 5 years, and $37 \% \pm 9 \%$ at 10 years (Figure 2). In the TAVR cohort, Kaplan-Meier estimate of mortality at 1 year was $11 \% \pm 1 \%$, but only 5 patients were at risk 1 year after operation (Figure E1).

\section{Repeat Operation}

Clinical follow-up was obtained in all patients at 2.5 years (0.8-7.8) and at 1.0 year $(0.3-2.5)$ in the TAVR group and 5.2 years (1.2-8.6) in the SAVR group. Repeat cardiac procedures were performed in 5 of 37 patients $(14 \%)$ who survived the index operation in the SAVR group. Operations included repeat aortic valve replacement, transcatheter aortic valve-in-valve replacement, and mitral valve clip insertion, whereas those in the repeat composite valve/ root replacement group underwent repeat composite aortic valve/root replacement and repair of an ascending aortic pseudoaneurysm. There were no repeat cardiac procedures in the TAVR group.

\section{DISCUSSION}

In this study, we analyzed our experience with a failing aortic root homograft in 51 patients who received repeat aortic valve replacement that included TAVR $(\mathrm{n}=11)$ or SAVR $(\mathrm{n}=40)$. We found that both TAVR and SAVR were associated with notable operative risk and comparable short- to intermediate-term mortality outcomes; however, the TAVR approach was associated with a low rate of bleeding (major or life-threatening, and as noted by need for less blood product transfusion) and short length of hospital stay. We also identified an important conical frustum geometric shape of the aortic homograft annulus and left ventricular outflow tract. The discrepant geometric areas of the top (ie, aortic valve annulus) and base (ie, left ventricular outflow tract) confound the sizing of the transcatheter aortic valve.

Repeat SAVR is technically challenging in the setting of a failing aortic root homograft. In our surgical group, only 10 patients $(25 \%)$ were treated with aortic valve replacement. The majority, 30 patients $(75 \%)$, received repeat composite aortic valve/root replacement. The need for such an extensive operation has also been reported by other investigators. In their study of 21 patients of repeat aortic replacement in the setting of failing aortic root homograft, Sundt and colleagues ${ }^{1}$ reported repeat composite aortic valve/root replacement in 9 patients $(43 \%)$. A similar experience was reported in 20 patients by Joudinaud and associates, ${ }^{2}$ who performed repeat composite aortic valve/root replacement in 9 patients $(45 \%)$. Review of these studies demonstrates that SAVR carries with it a notable risk of blood transfusion, morbidity, and mortality. ${ }^{1-5}$ The use of a rapid-deployment aortic valve may lessen these risks, because it may alleviate the need for repeat composite aortic valve/root replacement. ${ }^{17}$

Repeat SAVR can be a complex operation in the setting of a failing aortic root homograft. Removing the calcified homograft root can be difficult enough, but many of these patients also present with important concomitant cardiac pathologies. In our SAVR group, concomitant procedures were carried out in $58 \%$ of patients. Additional procedures included ascending aorta replacement in $28 \%$ of patients, aortic root enlargement in $18 \%$, coronary artery bypass graft operation in $18 \%$, and a mitral or tricuspid valve procedure in upwards of $15 \%$. It is also important to point out that we observed a $15 \%$ rate of sternal entry injury. These concomitant cardiac operations and sternal entry injury rates are similar to those reported by other 
investigators. ${ }^{1-5}$ We suspect that this additional operative burden contributed to the notable procedure-related blood transfusion requirement, morbidity, and mortality.

Our TAVR experience is limited with only 11 cases operated between 2014 and 2018, but the initial review of the experience is that this approach to a failing aortic root homograft was associated with favorable outcomes. Notwithstanding our high rate of vascular injury (which can certainly be improved upon), we noted excellent hemodynamic function and acceptable TAVR procedure-related and intermediate-term outcomes. We think these outcomes are consistent with previously published case reports and case series in which all reported patients survived operation to be discharged from the hospital. ${ }^{6-13}$ In the largest case series published that included 5 patients, every patient was alive at a follow-up at 322 days. ${ }^{12}$ Paravalvular aortic valve regurgitation has not been an issue in our or the reported experience. $^{6-13}$

An additional issue related to the TAVR procedure is that concomitant cardiac pathology often must be left untreated. For instance, we had 2 patients with significant coronary artery stenosis (50\% left main coronary artery stenosis) and 2 patients with moderate mitral valve regurgitation who did not have those problems addressed at the time of transcatheter valve replacement. The paradigm of not treating concomitant cardiac valve pathology has been reported to be reasonable and safe, as noted by Little and colleagues ${ }^{18}$ in the extreme-risk CoreValve pivotal study. We remain cautious of this strategy, however, given the limited duration of follow-up in our TAVR group. The long-term impact of not treating such pathology at the time of TAVR for failing homograft aortic root remains to be determined. Additional factors that play into the controversy include the patient's age and associated comorbidity. Is leaving concomitant cardiac pathology untreated a benefit (ie, less operative insult) or a disadvantage (ie, future cardiac morbidity)?

We have identified an important geometric shape of the failing aortic root homograft. The aortic valve annulus geometric area is relatively smaller in comparison with the left ventricular outflow tract geometric area, much like a conical frustum (Figure 1). In our analysis, multidetector computed tomography calculation of the aortic valve annulus geometric area was $512 \mathrm{~mm}^{2}$ (IQR, 435-630), and that of the left ventricular outflow tract geometric area was larger at $677 \mathrm{~mm}^{2}$ (IQR, 490-780; $P=.002$ ). The controversy is whether to size the transcatheter valve to the geometric area of the aortic annulus or the left ventricular outflow tract. We are not sure of the answer, but we have tended to size to the larger left ventricular outflow tract. Our sizing paradigm is in contrast to that of Barbanti and colleagues, ${ }^{19}$ who recommend under-expansion to avoid annular rupture. The aortic root homograft annulus represents the homograft-native annulus suture line (ie, neo-annulus). In our experience, this neo-annulus is usually heavily scarred and calcified, and rupture was not observed.

\section{Study Limitations}

This study has several limitations, the most important of which is our cohort of only 51 patients included with just 11 in the TAVR group. Given the limited number of patients, this study is at risk for type II statistical error in accepting the null hypothesis that TAVR is a safe option for the treatment of the failing aortic root homograft. Our study was not randomized, so we could not control for differences between patients selected for each of the surgical approaches. Because of our limited experience, as well as that of others, we cannot comment on the risk/benefits of balloonexpandable versus self-expanding valve choice. Finally, the surgical cases were operated during an 18-year span; it is possible that changes in clinical practice, patient characteristics, and comorbidity loads over time may have influenced our findings.

\section{CONCLUSIONS}

There is limited published experience comparing the outcomes of TAVR and SAVR in the setting of the failing aortic root homograft. Our experience, and most data, would support SAVR to be associated with notable rates of blood transfusion, morbidity, and mortality. Notwithstanding our high rate of vascular injury, our procedural outcomes were generally good and acceptable after TAVR. The present case series adds important information when considering TAVR. Special consideration is warranted to size the valve understanding the conical frustum type discrepancy in geometric areas between the aortic valve annulus and the left ventricular outflow tract. We favor using the left ventricular outflow tract geometric area. It is unclear as to the risk/benefit of a balloon-expandable versus selfexpanding valve. Further extended duration of follow-up is needed to define the long-term outcomes in the TAVR group.

\section{Conflict of Interest Statement}

J.A.C. reports grants from Medtronic and Boston Scientific, outside the submitted work. J.A.C. and G.S.S. report personal fees for serving on the Advisory Board of Medtronic. All other authors have nothing to disclose with regard to commercial support.

\footnotetext{
References

1. Sundt TM III, Rasmi N, Wong K, Radley-Smith R, Khaghani A, Yacoub MH. Reoperative aortic valve operation after homograft root replacement: surgical options and results. Ann Thorac Surg. 1995;60:S95-100.

2. Joudinaud TM, Baron F, Raffoul R, Pagis B, Vergnat M, Parisot C, et al. Redo aortic root surgery for failure of an aortic homograft is a major technical challenge. Eur J Cardiothorac Surg. 2008;33:989-94.

3. Hahn C, Tam SKC, Vlahakes GJ, Hilgenberg AD, Akins CW, Buckley MJ. Repeat aortic root replacement. Ann Thorac Surg. 1998;66:88-91.
} 
4. Kowert A, Vogt F, Beiras-Fernandez A, Reichart B, Kilian E. Outcome after homograft redo operation in aortic position. Eur J Cardiothorac Surg. 2012;41:404-8.

5. Kumar P, Athanasiou T, Ali A, Nair S, Oz BS, DeSouza A, et al. Re-do aortic valve replacement: does a previous homograft influence the operative outcome? J Heart Valve Dis. 2004;13:904-12.

6. Olsen LK, Engstrøm T, Søndergaard L. Transcatheter valve-in-valve implantation due to severe aortic regurgitation in a degenerated aortic homograft. J Invasive Cardiol. 2009;21:E197-200.

7. Alsidwadi S, Greason KL, Sandhu GS, Malouf JF, Chandrasekaran K. Percutaneous valve-in-homograft for management of a failed homograft. Eur Heart $J$ Cardiovasc Imaging. 2016;10:1190.

8. Attia R, Visagan R, Nowell J, Chadalavada S, Thomas M, Bapat V. Transapical transcatheter aortic valve implantation in a complex aortic surgical patient: a case involving the youngest valve-in-valve implantation with a $29 \mathrm{~mm}$ transcatheter valve. Exp Clin Cardiol. 2012;17:251-3.

9. Otalvaro L, Alfonso CE, O'Neill WW, O'Neill BP, Heldman AW. Transfemoral aortic valve replacement in failing aortic root homografts. J Card Surg. 2014;29: 333-6.

10. Dainese L, Fusari M, Trabattoni P, Biglioli P. Redo in aortic homograft replacement: transcatheter aortic valve as a valid alternative to surgical replacement. J Thorac Cardiovasc Surg. 2010;139:1656-7.

11. Díez JG, Schechter M, Dougherty KG, Preventza O, Coselli JS. Transcatheter aortic valve-in-valve replacement instead of a 4th sternotomy in a 21-year-old woman with aortic homograft failure. Tex Heart Inst J. 2016;43:334-7.

12. Lopez-Otero D, Teles R, Gomez-Hospital JA, Balestrini CS, Romaguera R, Saaibi-Solano JF, et al. Transcatheter aortic valve implantation: safety and effectiveness of the treatment of degenerated aortic homograft. Rev Esp Cardiol. 2012; 65:350-5.
13. Hollander KN, Montealegre-Gallegos M, Mahmood F. Valve-in-valve-in homograft: a case of a repeat transcatheter aortic valve replacement in a patient with an aortic homograft. Ann Card Anaesth. 2016;19:737-9.

14. Transcatheter Heart Valve with the Edwards Commander Delivery System. Irvine, CA: Edwards Lifesciences LLC; 2014.

15. Transcatheter Aortic Valve Delivery Catheter System Compression Loading System. Santa Ana, CA: Medtronic CoreValve LLC; 2014.

16. Kappatein AP, Head SJ, Genereux P, Piazza N, van Miegham NM Blackstone EH, et al. Updated standardized endpoint definitions for transcatheter aortic valve implantation: the valve academic research consortium-2 consensus document. J Thorac Cardiovasc Surg. 2013;145:6-23.

17. Danesi TH, Minniti G, Cresce GD, Favaro A, Magagan P, Auriemma S, et al Redo after failure of aortic homografts with a rapid deployment valve. Ann Thorac Surg. 2016;102:e281-2.

18. Little SH, Popma JJ, Kleiman NS, Deeb GM, Gleason TG, Yakubov SJ, et al. Transcatheter aortic valve replacement in patients with severe mitral or tricuspid regurgitation at extreme risk for surgery. J Thorac Cardiovasc Surg. 2018;155: 1991-9.

19. Barbanti M, Leipsic J, Binder R, Dvir D, Tan J, Freeman M, et al. Underexpansion and ad hoc post-dilation in selected patients undergoing balloonexpandable transcatheter aortic valve replacement. J Am Coll Cardiol. 2014;63:976-81.

Key Words: transcatheter valve insertion, transcatheter valve replacement, homograft failure, homograft senescence, surgical aortic valve replacement, valve in valve 


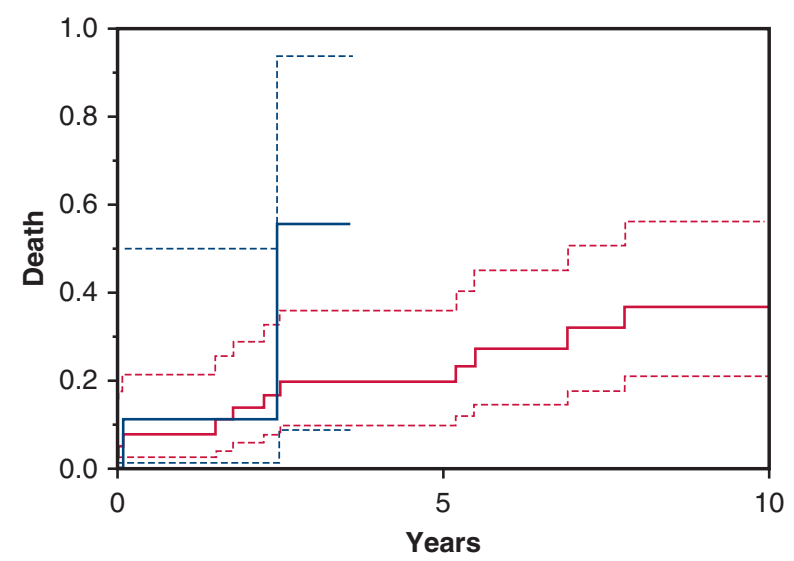

FIGURE E1. Kaplan-Meier estimates of mortality in the TAVR and SAVR groups.

TABLE E1. Operative data in surgical aortic valve replacement group, stratified by aortic valve replacement and repeat composite aortic valve/ root replacement

\begin{tabular}{|c|c|c|c|c|}
\hline Variable & $\begin{array}{l}\text { All SAVR patients } \\
\qquad(\mathrm{n}=\mathbf{4 0})\end{array}$ & $\begin{array}{c}\text { Aortic valve } \\
\text { replacement }(n=10)\end{array}$ & $\begin{array}{l}\text { Repeat composite aortic valve/ } \\
\text { root replacement }(n=30)\end{array}$ & $P$ value \\
\hline Cardiopulmonary bypass time (min) & $186(149-250)$ & $149(91-226)$ & $200(158-253)$ & .080 \\
\hline Aortic crossclamp time (min) & $135(110-198)$ & $112(66-166)$ & $144(120-199)$ & .055 \\
\hline $\begin{array}{l}\text { Valve type } \\
\text { Mechanical } \\
\text { Biological stented } \\
\text { Biological stentless }\end{array}$ & $\begin{array}{c}33(83) \\
6(15) \\
1(3)\end{array}$ & $\begin{array}{l}6(60) \\
4(40) \\
0(0)\end{array}$ & $\begin{array}{l}27(90) \\
2(7) \\
1(3)\end{array}$ & $.035^{*}$ \\
\hline \multicolumn{5}{|l|}{ Concomitant procedure } \\
\hline Any & $23(58)$ & $7(70)$ & $16(53)$ & .471 \\
\hline Ascending aorta replacement & $11(22)$ & $3(30)$ & $8(27)$ & 1.000 \\
\hline Coronary artery bypass graft operation & $7(18)$ & $1(10)$ & $6(20)$ & .656 \\
\hline Aortic root enlargement & $7(18)$ & $4(40)$ & $3(10)$ & .052 \\
\hline Mitral valve operation & $6(15)$ & $3(30)$ & $3(10)$ & .153 \\
\hline Cabrol modification & $5(13)$ & $0(0)$ & $5(17)$ & .306 \\
\hline Tricuspid valve operation & $3(8)$ & $1(10)$ & $2(7)$ & 1.000 \\
\hline
\end{tabular}

Continuous data were analyzed with the nonparametric rank-sum test. SAVR, Surgical aortic valve replacement. *Categoric data were analyzed with the Fisher exact with exception of the $2 \times 3$ contingency table that was analyzed with the chi-square test. 
TABLE E2. Blood transfusion data

\begin{tabular}{|c|c|c|c|c|}
\hline Variable & All patients $(n=51)$ & $\operatorname{TAVR}(\mathbf{n}=\mathbf{1 1})$ & $\operatorname{SAVR}(n=40)$ & $P$ value \\
\hline Blood transfusion (any) & $34(67)$ & $2(18)$ & $32(80)$ & $<.001$ \\
\hline Packed red blood cells $>4$ units & $10(20)$ & $0(0)$ & $10(25)$ & .094 \\
\hline All blood $>4$ units & $24(47)$ & $0(0)$ & $24(60)$ & $<.001$ \\
\hline Packed red blood cells (units) & $2(0-4)$ & $0(0)$ & $2(0-5)$ & .002 \\
\hline Fresh-frozen plasma (units) & $2(0-4)$ & $0(0)$ & $3(0-5)$ & $<.001$ \\
\hline Cryoprecipitate (units) & $0(0-2)$ & $0(0)$ & $0(0-2)$ & .014 \\
\hline Platelets (units) & $1(0-2)$ & $0(0)$ & $1(0-2)$ & $<.001$ \\
\hline Total (units) & $4(0-12)$ & $0(0)$ & $7(1-14)$ & $<.001$ \\
\hline
\end{tabular}

